\title{
Predicting severe or critical symptoms in hospitalized patients with COVID-19 from Yichang, China
}

\author{
Xin Chen ${ }^{1,}{ }^{*}$, Feng Peng ${ }^{1,}{ }^{*}$, Xiaoni Zhou ${ }^{2}$, Jiang Zhu $^{1}$, Xin Chen ${ }^{3}$, Yingying Gong ${ }^{3}$, Wang Shupeng ${ }^{3}$, \\ Wenquan $\mathrm{Niu}^{4}$ \\ ${ }^{1}$ Department of Cardiology, The First Affiliated Hospital of Fujian Medical University, Fuzhou, Fujian, China \\ ${ }^{2}$ Department of Pulmonary Disease, The Third People's Hospital of Yichang, Yichang, Hubei, China \\ ${ }^{3}$ Department of Cardiology Nursing Center, The First Affiliated Hospital of Fujian Medical University, Fuzhou, \\ Fujian, China \\ ${ }^{4}$ Institute of Clinical Medical Sciences, China-Japan Friendship Hospital, Beijing, China \\ *Equal contribution
}

Correspondence to: Feng Peng, Wenquan Niu; email: pengfeng@fjmu.edu.cn, niuwenquan@zryhyy.com.cn Keywords: COVID-19, severe or critical symptoms, nomogram, prediction, risk

Received: August 20, $2020 \quad$ Accepted: November 8, $2020 \quad$ Published: December 9, 2020

Copyright: (C) 2020 Chen et al. This is an open access article distributed under the terms of the Creative Commons Attribution License (CC BY 3.0), which permits unrestricted use, distribution, and reproduction in any medium, provided the original author and source are credited.

\section{ABSTRACT}

Objectives: We aimed to identify potential risk factors for severe or critical coronavirus disease 2019 (COVID19) and establish a prediction model based on significant factors.

Methods: A total of $\mathbf{3 7 0}$ patients with COVID-19 were consecutively enrolled at The Third People's Hospital of Yichang from January to March 2020. COVID-19 was diagnosed according to the COVID-19 diagnosis and treatment plan released by the National Health and Health Committee of China. Effect-size estimates are summarized as odds ratio (OR) and $95 \%$ confidence interval (CI).

Results: 326 patients were diagnosed with mild or ordinary COVID-19, and 44 with severe or critical COVID19. After propensity score matching and statistical adjustment, eight factors were significantly associated with severe or critical COVID-19 $(p<0.05)$ relative to mild or ordinary COVID-19. Due to strong pairwise correlations, only five factors, including diagnostic delay (OR, $95 \% \mathrm{Cl}, p: 1.08,1.02$ to $1.17,0.048)$, albumin $(0.82,0.75$ to $0.91,<0.001)$, lactate dehydrogenase $(1.56,1.14$ to $2.13,0.011)$, white blood cell $(1.27,1.08$ to $1.50,0.004)$, and neutrophil $(1.40,1.16$ to $1.70,<0.001)$, were retained for model construction and performance assessment. The nomogram model based on the five factors had good prediction capability and accuracy (C-index: 90.6\%).

Conclusions: Our findings provide evidence for the significant contribution of five independent factors to the risk of severe or critical COVID-19, and their prediction was reinforced in a nomogram model.

\section{INTRODUCTION}

In late 2019, a novel human coronavirus, severe acute respiratory syndrome coronavirus 2 (SARS-CoV-2), was first identified in Wuhan, China. The syndrome of clinical symptoms caused by SARS-CoV-2 is labelled as coronavirus disease 2019 (COVID-19) [1]. In just over two months, COVID-19 had rapidly spread across the globe, and on 11 March 2020 it was declared a pandemic by the World Health Organization. As of July 29,2020 , there have been 16,558,289 confirmed cases of COVID-19, including 656,093 deaths across 216 countries, areas or territories (https://covid19.who.int/).

Clinically, COVID-19 can manifest on a spectrum of illnesses ranging from mild, self-limiting respiratory 
tract illness to severe progressive pneumonia, multiorgan failure, and death eventually $[2,3]$. The major symptoms of COVID-19 include fever, cough, fatigue, myalgia or arthralgia, sore throat, headache, shortness of breath, and sputum production [4]. High hopes have been pinned on the anti-HIV drug lopinavir-ritonavir in the treatment of COVID-19, yet the results are not satisfactory $[2,5,6]$. While no therapeutics have yet been proven effective and the true pathogenetic mechanisms of COVID-19 are not fully understood, the identification of risk factors in predicting the occurrence of critical illness in patients with COVID-19 is crucial to developing prevention strategies. Currently, several prediction models for COVID-19 diagnosis and prognosis have been established [7-10], with no consensus on their implications. Hence, the identification and characterization of risk profiling for the onset and progression of COVID-19 symptoms is still subject to exploration, improvement, and renewal.

To fill this gap in knowledge and yield more information for future studies, we, in 370 patients with COVID-19 consecutively admitted to The Third People's Hospital of Yichang, aimed to identify potential risk factors for severe or critical COVID-19 and establish a prediction nomogram model to facilitate clinical application.

\section{RESULTS}

\section{Baseline characteristics}

There were 326 patients diagnosed with mild or ordinary COVID-19, and 44 patients with severe or critical COVID-19. Of the 44 patients with severe or critical COVID-19, 16 were progressed from mild COVID-19 during hospitalization and 28 were initially diagnosed to have severe or critical COVID-19 at admission.

The baseline characteristics of these patients are provided in Supplementary Table 1. Of note, patients with severe or critical COVID-19 were significantly older than patients with mild or ordinary COVID-19 $(p$ $<0.001)$. Over $90 \%$ patients with severe or critical COVID-19 had contact with Wuhan, remarkably higher than that $(54.5 \%)$ in patients with mild or ordinary COVID-19 ( $p$ <0.001). Additionally, patients with severe or critical COVID-19 were more likely to be complicated with hypertension, diabetes, cerebrovascular disease, and cardiovascular disease than patients with mild or ordinary COVID-19 (all $p<0.01$ ). In view of these remarkable differences in above demographic characteristics, to counterbalance these differences, a propensity score matching method was employed accordingly.
After matching on age, sex, smoking, hypertension, diabetes, cerebrovascular disease, and cardiovascular disease, 43 patients with severe or critical COVID-19 and 70 patients with mild or ordinary COVID-19 were retained for the following analyses, and their baseline characteristics are summarized in Table 1.

\section{Identification of significant factors for severe or critical COVID-19}

As shown in Table 2, before adjustment, eight factors were in statistically significant association with the risk of severe or critical COVID-19 when compared with mild or ordinary COVID-19 $(p<0.05)$, including diagnostic delay, ALB, LDH, WBC, HGB, LYMPH, MONO, and NEUT. After adjusting for age, sex, smoking, hypertension, diabetes, cerebrovascular disease, and cardiovascular disease, significance was retained for all eight factors, especially for ALB $(\mathrm{OR}=0.82,95 \% \mathrm{CI}: 0.75$ to $0.91, p<0.001)$, LYMPH (OR=0.42, 95\% CI: 0.27 to $0.64, p<0.001)$, and NEUT (OR=1.40, 95\% CI: 1.16 to $1.70, p<0.001)$.

\section{Correlation analysis of significant factors for severe or critical COVID-19}

Spearman correlation analysis was performed to examine the pairwise relationship between eight significant factors (data not shown). Due to the strong correlation of HGB, LYMPH, and MONO with the other factors, they were not kept in the following analyses.

\section{Prediction performance of five independent significant factors}

Before model construction on the basis of five independent significant factors, a wide range of statistics were calculated to assess prediction accuracy from both calibration and discrimination aspects (Table 3 ), as well as from the net benefits gained by adding the five factors to the basic model (Figure 1). Multi-aspect analyses revealed that the contribution of the five factors to predict the occurrence of severe or critical COVID-19 was statistically significant.

\section{Establishment of prediction nomogram model}

To further analyze the joint contribution of five independent significant factors, a prediction nomogram model was established, as shown in Figure 2. The maximal prediction capability reached as high as $99 \%$, and calibration curve showed good prediction performance (Supplementary Figure 1), as reflected by the C-index $(90.6 \%, p<0.001)$. 
Table 1. The baseline characteristics of study patients with COVID-19 after propensity score matching.

\begin{tabular}{|c|c|c|c|}
\hline Characteristics & $\begin{array}{l}\text { Mild or ordinary cases } \\
\qquad(\mathrm{n}=\mathbf{7 0})\end{array}$ & $\begin{array}{l}\text { Severe or critical cases } \\
\qquad(n=43)\end{array}$ & $p$ \\
\hline Age (years) & $66(55,73)$ & $70(58,79)$ & 0.089 \\
\hline Males & $38(54.3 \%)$ & $23(53.5 \%)$ & 0.934 \\
\hline Contact with WH & $20(31.7 \%)$ & $39(90.7 \%)$ & $<0.001$ \\
\hline Death & $0(0 \%)$ & $15(34.9 \%)$ & $<0.001$ \\
\hline Hypertension & $27(38.6 \%)$ & $21(48.8 \%)$ & 0.284 \\
\hline Diabetes & $9(12.9 \%)$ & $10(23.3 \%)$ & 0.151 \\
\hline Smoking & $11(15.7 \%)$ & $6(14 \%)$ & 0.799 \\
\hline Cerebrovascular disease & $3(4.3 \%)$ & $5(11.6 \%)$ & 0.140 \\
\hline Cardiovascular disease & $7(10.0 \%)$ & $9(20.9 \%)$ & 0.106 \\
\hline Diagnostic delay (days) & $3.500(2,6)$ & $6(3,10)$ & 0.005 \\
\hline WBC & $4.250(3.400,5.700)$ & $5.500(4.400,7.800)$ & 0.010 \\
\hline NEUT & $65.30(56.30,70.70)$ & $79.60(65.60,89.90)$ & $<0.001$ \\
\hline LYMPH & $26.20(17.50,33.30)$ & $13.70(6.900,22.90)$ & $<0.001$ \\
\hline MONO & $7.100(4.500,8.800)$ & $4.200(2.500,7.500)$ & 0.002 \\
\hline NEUT $\left(\times 10^{9} / \mathrm{L}\right)$ & $2.770(2.030,3.980)$ & $4.600(2.860,6.670)$ & 0.001 \\
\hline LYMPH $\left(\times 10^{9} / \mathrm{L}\right)$ & $1.130(0.780,1.430)$ & $0.760(0.530,1.030)$ & $<0.001$ \\
\hline $\operatorname{MONO}\left(\times 10^{9} / \mathrm{L}\right)$ & $0.275(0.200,0.370)$ & $0.280(0.200,0.360)$ & 0.455 \\
\hline $\operatorname{PLT}\left(\times 10^{9} / \mathrm{L}\right)$ & $123(102,173)$ & $134(88,182)$ & 0.795 \\
\hline PCT (ng/mL) & $0.100(0.0700,0.140)$ & $0.130(0.0800,0.270)$ & 0.069 \\
\hline TBIL $(\mu \mathrm{mol} / \mathrm{L})$ & $9.590(7.310,14.45)$ & $8.890(6.920,14.36)$ & 0.665 \\
\hline DBIL $(\mu \mathrm{mol} / \mathrm{L})$ & $2.410(1.790,3.870)$ & $3.050(2.210,4.960)$ & 0.060 \\
\hline $\operatorname{ALB}(g / L)$ & $37.10(33.70,41.20)$ & $29.60(27.40,36.10)$ & $<0.001$ \\
\hline ALT (UL) & $21(16,43)$ & $23(14,35)$ & 0.561 \\
\hline AST (UL) & $25(19,33)$ & $24(21,36)$ & 0.651 \\
\hline $\mathrm{Cr}(\mu \mathrm{mol} / \mathrm{L})$ & $69.75(57.60,80.20)$ & $65.70(54.50,86.30)$ & 0.546 \\
\hline CK (UL) & $66(42,106)$ & $80(45,130.5)$ & 0.485 \\
\hline CKMB (UL) & $13.15(10.50,16.10)$ & $15(9.900,26.20)$ & 0.392 \\
\hline $\mathrm{CRP}(\mathrm{mg} / \mathrm{L})$ & $27.60(7.100,67.10)$ & $40.10(13.20,66.30)$ & 0.270 \\
\hline LDH (UL) & $205(171,259)$ & $314(217,451)$ & $<0.001$ \\
\hline $\mathrm{HGB}(\mathrm{g} / \mathrm{L})$ & $119(109,129)$ & $114(97,122)$ & 0.007 \\
\hline
\end{tabular}

Abbreviations: WH, Wuhan; WBC, white blood cell; NEUT, neutrophil; LYMPH, lymphocyte; MONO, monocyte; PLT, platelet; PCT, procalcitonin; TBIL, total bilirubin; DBIL, direct bilirubin; ALB, albumin; ALT, alanine transaminase; AST, aspartate aminotransferase; $\mathrm{Cr}$, creatinine; $\mathrm{CK}$, creatine kinase; $\mathrm{CKMB}$, creatine phosphokinase-isoenzyme-MB; $\mathrm{CRP}, \mathrm{C}$-reactive protein; $\mathrm{LDH}$, lactate dehydrogenase; HGB, hemoglobin. The $p$ value was calculated using the rank sum test or $\chi^{2}$ test where appropriate. Data are expressed as median (interquartile range) or count (percentage).

\section{DISCUSSION}

Via a cross-sectional analysis of 370 hospitalized patients with COVID-19 at a tertiary hospital, Yichang city, in the same province where Wuhan city is located, we have identified five independent factors in significant association with severe or critical COVID-19 relative to mild or ordinary COVID-19, and their prediction 
Table 2. Identification of significant factors in association with severe or critical COVID-19 relative to mild or ordinary COVID-19.

\begin{tabular}{lcccccc}
\hline \multirow{2}{*}{ Significant factors } & \multicolumn{3}{c}{ Unadjusted } & \multicolumn{3}{c}{ Adjusted* } \\
\cline { 2 - 7 } & OR & $\mathbf{9 5 \%} \mathbf{C I}$ & $\boldsymbol{p}$ & $\mathbf{O R}$ & $\mathbf{9 5 \%} \mathbf{C I}$ & $\boldsymbol{p}$ \\
\hline Diagnostic delay (+1) & 1.08 & 1.01 to 1.16 & 0.036 & 1.08 & 1.02 to 1.17 & 0.048 \\
ALB (+1) & 0.84 & 0.77 to 0.91 & $<0.001$ & 0.82 & 0.75 to 0.91 & $<0.001$ \\
LDH (+100) & 1.61 & 1.15 to 2.27 & 0.006 & 1.56 & 1.14 to 2.13 & 0.011 \\
WBC (+1) & 1.24 & 1.06 to 1.46 & 0.007 & 1.27 & 1.08 to 1.50 & 0.004 \\
HGB (+10) & 0.68 & 0.53 to 0.88 & 0.004 & 0.68 & 0.52 to 0.90 & 0.008 \\
LYMPH (+10) & 0.42 & 0.28 to 0.64 & $<0.001$ & 0.42 & 0.27 to 0.64 & $<0.001$ \\
MONO (+1) & 0.85 & 0.75 to 0.97 & 0.019 & 0.85 & 0.75 to 0.98 & 0.019 \\
NEUT $(+1)$ & 1.37 & 1.14 to 1.64 & 0.001 & 1.40 & 1.16 to 1.70 & $<0.001$ \\
\hline
\end{tabular}

Abbreviations: OR, odds ratio; $95 \% \mathrm{Cl}, 95 \%$ confidence interval; $A L B$, albumin; $L D H$, lactate dehydrogenase; WBC, white blood cell; HGB, hemoglobin; LYMPH, lymphocyte; MONO, monocyte; NEUT, neutrophil. The $p$ value was calculated after adjusting for age, sex, smoking, hypertension, diabetes, cerebrovascular disease, and cardiovascular disease.

Table 3. Prediction performance for adding five significant factors to the basic model.

\begin{tabular}{lccc}
\hline Statistics & Basic model* $^{*}$ & \multicolumn{1}{c}{ Basic model + significant factors } \\
\hline AIC & 112 & & 60 \\
BIC & 131 & $<0.0013$ & 93 \\
LR test $(p)$ & & & 0.186 \\
HL test $(p)$ & 0.325 & 0.001 & \\
NRI $(p)$ & & $<0.001$ & \\
IDI $(p)$ & & & $0.96(0.91,1.00)$ \\
AUROC & $0.86(0.76,0.95)$ & 0.026 & \\
AUROC $(p)$ & & & \\
\hline
\end{tabular}

Abbreviations: AIC, Akaike information criterion; BIC, Bayesian information criterion; LR, likelihood ratio; HL test, HosmerLemeshow test; NRI, net reclassification improvement; IDI, integrated discrimination improvement; AUROC, area under the receiver operating characteristic. *Variables in the basic model included age, sex, smoking, hypertension, diabetes, cardiovascular disease, and cerebrovascular disease.

was reinforced in a nomogram model. The findings of this study can help enrich our understanding on the risk profiles for the progression of COVID-19 from mild or ordinary symptoms to severe or critical symptoms.

Waves of studies that have attempted to identify factors such as demographic characteristics, medical histories, laboratory biomarkers responsible for the onset and progression of COVID-19 symptoms are coming toward us like a tsunami since early 2020 [1120]. Currently, one of the pressing problems facing clinicians is that the significant factors identified by individual studies are not often reproducible. Besides inadequate statistical power due to small sample sizes, many times, such irreproducibility may be attributed to the failure to adequately adjust for confounding. Several techniques are recommended to control or reduce the impact of confounding factors, such as statistical adjustment, subsidiary exploration, and propensity score matching. Growing evidence indicates that multiple reports have shown underlying chronic health conditions such as hypertension, diabetes, cardiovascular disease, and cerebrovascular disease are overrepresented and tend to be associated with severe COVID-19 [4, 21-24], in line with the findings of the present cross-sectional analysis. To account for these established underlying chronic health conditions, we here employed the propensity score matching method to balance baseline covariates between patients with mild or ordinary COVID-19 and severe or critical COVID-19 


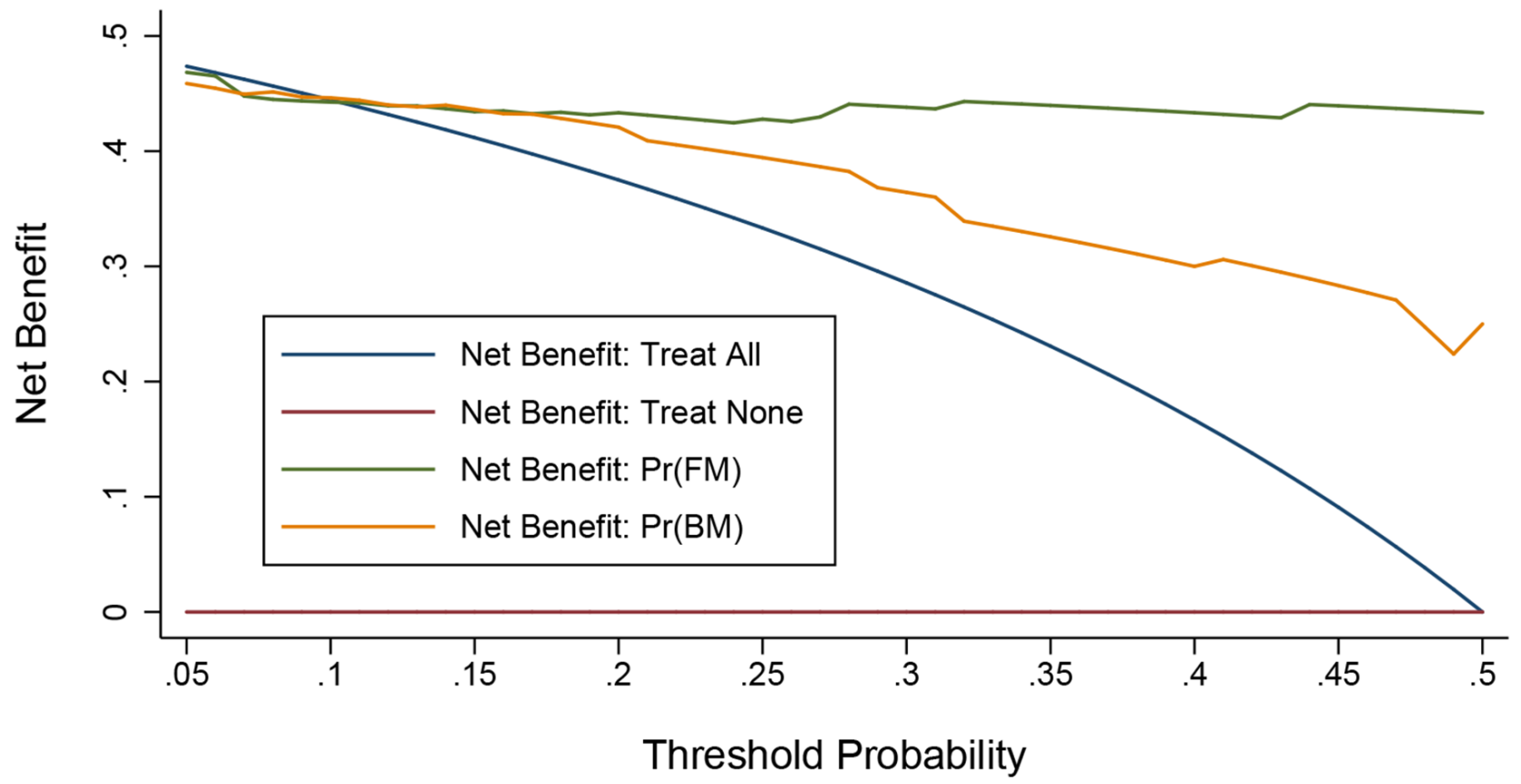

Figure 1. Decision curve analysis on the net benefits gained by adding significant factors to the basic model. Abbreviations: FM, full model; BM, basic model. The orange solid line corresponds to the basic model that includes age, sex, smoking, hypertension, diabetes, cardiovascular disease, and cerebrovascular disease. The green solid line corresponds to the full model that includes both factors in the basic model and the five newly-identified unrelated significant factors including diagnostic delay, albumin, lactate dehydrogenase, white blood cell, and neutrophil. Over threshold probabilities of 0.17 , the net benefit gained by adding the five significant factors was greater than that in the basic model.

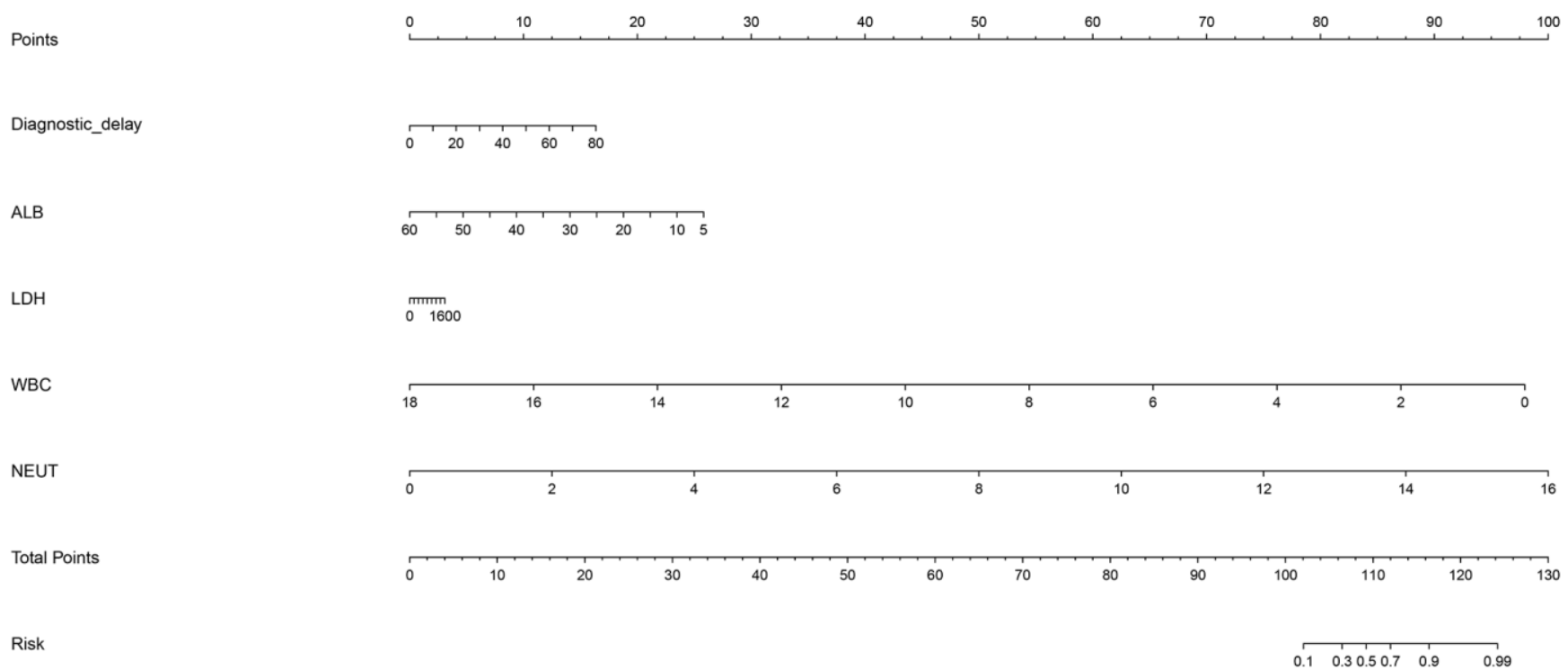

Figure 2. Prediction nomogram for the prediction of severe or critical COVID-19 relative to mild or ordinary COVID-19 based on the five newly-identified unrelated significant factors. Abbreviations: ALB, albumin; WBC, white blood cell; NEUT, neutrophil. This nomogram can be used to manually obtain predicted values from a regression model that was fitted with the five significant factors including diagnostic delay, albumin, lactate dehydrogenase, white blood cell, and neutrophil. In detail, there is a reference line at the top for reading scoring points (range: 0 to 100) from all factors in the regression model, which were summed together to calculate the total points, and then the predicted values can be read at the bottom. 
in order to "replicate" a randomized controlled trial. Propensity score matching is a tool for causal inference in non-randomized studies that allows for conditioning on large sets of covariates [25].

After propensity score matching and statistical adjustment, we identified five uncorrelated factors that were independently and statistically associated with the risk of having severe or critical COVID-19 relative to mild or ordinary COVID-19, including diagnostic delay, ALB, LDH, WBC, and NEUT, consistent with the findings of some recent studies [26-33]. Given the fact that clinical progression of COVID-19 symptoms is a multistep, multifactorial progress, it is unlikely that any one single factor would play a predominant part in this process. There is a wide recognition that a risk prediction model regressing multiple attributes is more imperative than reporting single significant attributes alone, because the contribution of a single attribute may be enhanced or shadowed by the concurrent presence of another attribute. To shed some light on this issue, we attempted to establish a prediction nomogram model on the basis of factors that were in week correlation, independent of demographic covariates, in significant association with severe or critical COVID-19, and exhibited decent prediction performance from multiple aspects. As expected, this nomogram model had good prediction capability and accuracy, albeit our analysis was based on mere $30 \%$ of original data after propensity score matching. In the literature, several studies have attempted to predict the severity and mortality of COVID-19 by using the nomogram technique [34-37], yet the factors modelled in the nomogram were not consistent studies, possibly due to differences in patient characteristics and statistical power, as well as possible residual confounding. As such, we expect further external validation of our significant findings in other independent populations.

Several limitations should be acknowledged for this study. Firstly, all study patients with COVID-19 were consecutively enrolled from a mono-center, and it could better be generalized pending consistently confirmed in other cohorts. Second, this study was designed in a cross-sectional pattern, and making references regarding causality is not allowed. Thirdly, assessable patients with COVID-19, especially with severe or critical symptoms are less than 50, which prohibits further subsidiary analyses to explore confounding effects. Fourthly, our findings were exclusively derived from a Chinese population, and external validation in other racial populations would be of added interest.

Taken together, our findings provide evidence for the significant contribution of five independent factors to the risk of severe or critical COVID-19 relative to mild or ordinary COVID-19. More importantly, a prediction nomogram model based on the five factors is useful for the identification of high-risk patients with mild or ordinary COVID-19 in predisposition to severe or critical symptoms.

\section{MATERIALS AND METHODS}

\section{Study patients}

All study patients, who were confirmed to be infected with COVID-19, were consecutively enrolled at The Third People's Hospital of Yichang, Yichang city, Hubei province, China during the period from January to March 2020. They received medical treatment and/or standard care for COVID-19 after infection in this hospital. All patients willingly gave written informed consent for participation after a full explanation of the procedures associated with this study. No restrictions were imposed with regard to the age, gender, and ethnicity or COVID-19 severity of affected patients under study.

\section{Diagnosis of COVID-19}

COVID-19 was diagnosed according to the coronavirus disease 2019 diagnosis and treatment plan (tentative sixth edition) released by the National Health and Health Committee of China [38, 39]. The confirmation of COVID-19 was made by the 2019-Novel Coronavirus (2019-nCoV) Real-time PCR Kit.

\section{Severity criteria of COVID-19}

According to the coronavirus disease 2019 diagnosis and treatment plan (tentative sixth edition) released by the National Health and Health Committee of China [38, 39], patients with COVID-19 can be classified into four clinical types, that is, mild cases, ordinary cases, severe cases, and critical cases. Mild cases refer to mild clinical symptoms and no detectable pneumonia manifestation in imaging. Ordinary cases include patients who have symptoms like fever and respiratory tract symptoms and detectable pneumonia manifestation in imaging. Severe cases are recorded if any of the following items is met: (a) respiratory distress, respiratory rate $\geq 30$ breaths/min; (b) pulse oxygen saturation ( $\mathrm{SpO} 2) \leq 93 \%$ on room air at rest state; (c) arterial partial pressure of oxygen $(\mathrm{PaO} 2) /$ fraction of inspired oxygen $(\mathrm{FiO} 2) \leq 300 \mathrm{mmHg}$. At higher altitudes (above $1 \mathrm{~km}$ ), $\mathrm{PaO} 2 / \mathrm{FiO} 2$ values should be adjusted based on equation of $\mathrm{PaO} 2 / \mathrm{FiO} 2 \times$ [Atmospheric Pressure (mmHg)/760]; (d) patients with $>50 \%$ lesions progression within 24 to $48 \mathrm{~h}$ in pulmonary imaging. Critical cases are recorded if any of the following items is met: (a) respiratory failure occurs and 
mechanical ventilation is required; (b) shock occurs; (c) complicated with other organ failure that requires monitoring and treatment in Intensive Care Unit (ICU).

\section{Demographic information}

After informed written consent, all eligible patients were interviewed and demographic information was recorded, including age at admission, gender, contact with Wuhan citizens, cigarette smoking, hypertension, diabetes, cerebrovascular disease, cardiovascular disease, and diagnostic delay (days). Cigarette smoking is grouped into never smoking and ever smoking, and ever smoking includes former and current smoking. Hypertension is defined as systolic blood pressure (SBP) of $\geq 140 \mathrm{~mm} \mathrm{Hg}$, diastolic blood pressure (DBP) of $\geq 90 \mathrm{~mm} \mathrm{Hg}$, or current use of antihypertensive medicine. Diabetes is defined as fasting plasma glucose concentration $\geq 7.0 \mathrm{mmol} / \mathrm{L}$ or a self-reported diagnosis. Diagnostic delay refers to the time between onset of symptoms and first diagnosis of COVID-19, and is recorded in days.

\section{Laboratory biomarkers}

Laboratory biomarkers were measured at the time of enrollment, including white blood cell (WBC), neutrophil (NEUT), lymphocyte (LYMPH), monocyte (MONO), platelet (PLT), procalcitonin (PCT), total bilirubin (TBIL), direct bilirubin (DBIL), albumin (ALB), alanine transaminase (ALT), aspartate aminotransferase (AST), creatinine ( $\mathrm{Cr}$ ), creatine kinase (CK), creatine phosphokinase-isoenzyme-MB (CKMB), C-reactive protein (CRP), lactate dehydrogenase (LDH), and hemoglobin (HGB). All biomarkers were assayed at the Laboratory Department of The Third People's Hospital of Yichang.

\section{Statistical analyses}

Continuous data are summarized as median (interquartile range), and categorical data are summarized as count (percentage). Two-group comparison was done by using the Wilcoxon ranksum test or $\chi^{2}$ test, when appropriate. Propensity score matching method was used to balance confounding factors, and it was implemented by using the order "psmatch2" in the STATA software (v14.1). Logistic regression analysis was used to identify potential risk factors for severe or critical COVID-19 relative to mild or ordinary COVID-19 before and after adjusting for confounding factors. Prediction accuracy was statistically assessed using calibration and discrimination statistics, including Akaike information criterion (AIC), Bayesian information criterion (BIC), likelihood ratio (LR) test, HosmerLemeshow (HL) test, net reclassification improvement
(NRI), integrated discrimination improvement (IDI), and area under the receiver operating characteristic (AUROC), as well as visually by decision curve analysis (DCA). Finally, based on the significant factors, a prediction nomogram model was established in prediction of severe or critical COVID-19. In addition, a calibration curve was plotted and $\mathrm{C}$-index was estimated to assess prediction performance. Nomogram, calibration curve, and Cindex were implemented by the "RMS" package (v3.6.3) in the $\mathrm{R}$ software (v3.6.1). The STATA software (v14.1) was used for statistical analyses unless otherwise illustrated.

\section{Ethical approval}

The conduct of this study was reviewed and approved by both Ethics Committees of The Third People's Hospital of Yichang and The First Affiliated Hospital of Fujian Medical University (Approval No. MRCTA, ECFAH of FMU 2020-153).

\section{Data availability statement}

Data involved in this study are available upon reasonable request.

\section{AUTHOR CONTRIBUTIONS}

F.P., X.Z., and W.N. planned and designed the study and directed its implementation. F.P. and X.C. $\left(1^{\text {st }}\right)$ drafted the protocol. F.P., X.C. $\left(1^{\text {st }}\right)$, X.Z., X.C. $\left(5^{\text {th }}\right)$, and Y.G. obtained statutory and ethics approvals. F.P. and X.C. $\left(1^{\text {st }}\right)$ contributed to data acquisition. F.P. and W.N. conducted statistical analyses. F.P., X.C. $\left(1^{\text {st }}\right)$, and W.N. did the data preparation and quality control. W.N. wrote the manuscript. All authors read and approved the final manuscript prior to submission.

\section{CONFLICTS OF INTEREST}

The authors declare that they have no conflicts of interest.

\section{FUNDING}

This work was sponsored by Fujian Provincial Health Technology Project (Grant number: 2019-CX-28), and Startup Fund for Scientific Research of Fujian Medical University (Grant number: 2019QH1076).

\section{REFERENCES}

1. Domingo P, Mur I, Pomar V, Corominas H, Casademont $\mathrm{J}$, de Benito $\mathrm{N}$. The four horsemen of a viral apocalypse: the pathogenesis of SARS-CoV-2 infection (COVID-19). EBioMedicine. 2020; 58:102887. 
https://doi.org/10.1016/i.ebiom.2020.102887 PMID: $\underline{32736307}$

2. Cao B, Wang Y, Wen D, Liu W, Wang J, Fan G, Ruan L, Song B, Cai Y, Wei M, Li X, Xia J, Chen N, et al. A Trial of Lopinavir-Ritonavir in Adults Hospitalized with Severe Covid-19. N Engl J Med. 2020; 382:1787-1799.

https://doi.org/10.1056/NEJMoa2001282

PMID:32187464

3. Wiersinga WJ, Rhodes A, Cheng AC, Peacock SJ, Prescott HC. Pathophysiology, transmission, diagnosis, and treatment of coronavirus disease 2019 (COVID19): a review. JAMA. 2020; 324:782-93. https://doi.org/10.1001/jama.2020.12839 PMID: $\underline{32648899}$

4. Guan WJ, Ni ZY, Hu Y, Liang WH, Ou CQ, He JX, Liu L, Shan H, Lei CL, Hui DS, Du B, Li L, Zeng G, et al, and China Medical Treatment Expert Group for Covid-19. Clinical characteristics of coronavirus disease 2019 in China. N Engl J Med. 2020; 382:1708-20. https://doi.org/10.1056/NEJMoa2002032 PMID:32109013

5. Griffin S. Covid-19: lopinavir-ritonavir does not benefit hospitalised patients, UK trial finds. BMJ. 2020; 370:m2650.

https://doi.org/10.1136/bmj.m2650 PMID:32611587

6. Hung IF, Lung KC, Tso EY, Liu R, Chung TW, Chu MY, Ng YY, Lo J, Chan J, Tam AR, Shum HP, Chan V, Wu AK, et al. Triple combination of interferon beta-1b, lopinavir-ritonavir, and ribavirin in the treatment of patients admitted to hospital with COVID-19: an open-label, randomised, phase 2 trial. Lancet. 2020; 395:1695-704.

https://doi.org/10.1016/S0140-6736(20)31042-4 PMID:32401715

7. Liang $W$, Liang $H$, Ou L, Chen B, Chen A, Li C, Li Y, Guan W, Sang L, Lu J, Xu Y, Chen G, Guo H, et al. Development and Validation of a Clinical Risk Score to Predict the Occurrence of Critical Illness in Hospitalized Patients With COVID-19. JAMA Intern Med. 2020; 180:1081-1089.

https://doi.org/10.1001/jamainternmed.2020.2033

PMID:32396163

8. Al-Najjar $\mathrm{H}, \mathrm{Al}-$ Rousan N. A classifier prediction model to predict the status of coronavirus COVID-19 patients in South Korea. Eur Rev Med Pharmacol Sci. 2020; 24:3400-03.

https://doi.org/10.26355/eurrev_202003 20709 PMID: $\underline{32271458}$

9. Singh RK, Rani M, Bhagavathula AS, Sah R, RodriguezMorales AJ, Kalita H, Nanda C, Sharma S, Sharma YD, Rabaan AA, Rahmani J, Kumar P. Prediction of the COVID-19 pandemic for the top 15 affected countries: advanced autoregressive integrated moving average (ARIMA) model. JMIR Public Health Surveill. 2020; 6:e19115.

https://doi.org/10.2196/19115 PMID:32391801

10. Sanchez-Caballero S, Selles MA, Peydro MA, PerezBernabeu E. An efficient COVID-19 prediction model validated with the cases of China, Italy and Spain: total or partial lockdowns? J Clin Med. 2020; 9:1547. https://doi.org/10.3390/jcm9051547 PMID:32443871

11. Zheng X, Chen J, Deng L, Fang Z, Chen G, Ye D, Xia J, Hong Z. Risk factors for the COVID-19 severity and its correlation with viral shedding: a retrospective cohort study. J Med Virol. 2020. [Epub ahead of print]. https://doi.org/10.1002/jmv.26367 PMID: $\underline{32725915}$

12. Xiong TY, Huang FY, Liu Q, Peng Y, Xu YN, Wei JF, Li N, Bai B, Li JH, Prendergast B, Li WM, Chen $M$. Hypertension is a risk factor for adverse outcomes in patients with coronavirus disease 2019: a cohort study. Ann Med. 2020; 52:361-66. https://doi.org/10.1080/07853890.2020.1802059 PMID: $\underline{32716217}$

13. Sanchez-Pina JM, Rodríguez Rodriguez $M$, Castro Quismondo N, Gil Manso R, Colmenares R, Gil Alos D, Paciello ML, Zafra D, Garcia-Sanchez C, Villegas C, Cuellar C, Carreño-Tarragona G, Zamanillo I, et al. Clinical course and risk factors for mortality from COVID-19 in patients with haematological Malignancies. Eur J Haematol. 2020; 105:597-607. https://doi.org/10.1111/ejh.13493 PMID:32710500

14. van Gerwen M, Alsen M, Little C, Barlow J, Genden E, Naymagon L, Tremblay D. Risk factors and outcomes of COVID-19 in new york city; a retrospective cohort study. J Med Virol. 2020; 10:1002.

https://doi.org/10.1002/imv.26337 PMID:32706392

15. Grasselli G, Greco M, Zanella A, Albano G, Antonelli M, Bellani G, Bonanomi E, Cabrini L, Carlesso E, Castelli G, Cattaneo S, Cereda D, Colombo S, et al, and COVID-19 Lombardy ICU Network. Risk factors associated with mortality among patients with COVID-19 in intensive care units in lombardy, Italy. JAMA Intern Med. 2020; 180:1345-55.

https://doi.org/10.1001/jamainternmed.2020.3539 PMID:32667669

16. Gupta S, Hayek SS, Wang W, Chan L, Mathews KS, Melamed ML, Brenner SK, Leonberg-Yoo A, Schenck EJ, Radbel J, Reiser J, Bansal A, Srivastava A, et al, and STOP-COVID Investigators. Factors associated with death in critically ill patients with coronavirus disease 2019 in the US. JAMA Intern Med. 2020; 180:1-12. https://doi.org/10.1001/jamainternmed.2020.3596 PMID: $\underline{32667668}$ 
17. Liao D, Zhou F, Luo L, Xu M, Wang H, Xia J, Gao Y, Cai L, Wang Z, Yin P, Wang $Y$, Tang L, Deng J, et al. Haematological characteristics and risk factors in the classification and prognosis evaluation of COVID-19: a retrospective cohort study. Lancet Haematol. 2020; 7:e671-78.

https://doi.org/10.1016/S2352-3026(20)30217-9 PMID: 32659214

18. Williamson EJ, Walker AJ, Bhaskaran K, Bacon S, Bates C, Morton CE, Curtis HJ, Mehrkar A, Evans D, Inglesby P, Cockburn J, McDonald HI, MacKenna B, et al. OpenSAFELY: factors associated with COVID-19 death in 17 million patients. Nature. 2020; 584:430-36. https://doi.org/10.1038/s41586-020-2521-4 PMID:32640463

19. Albitar O, Ballouze R, Ooi JP, Sheikh Ghadzi SM. Risk factors for mortality among COVID-19 patients. Diabetes Res Clin Pract. 2020; 166:108293. https://doi.org/10.1016/j.diabres.2020.108293 PMID: $\underline{32623035}$

20. Chen L, Yu J, He W, Chen L, Yuan G, Dong F, Chen W, Cao Y, Yang J, Cai L, Wu D, Ran Q, Li L, et al. Risk factors for death in 1859 subjects with COVID-19. Leukemia. 2020; 34:2173-83.

https://doi.org/10.1038/s41375-020-0911-0 PMID:32546725

21. Yang $X, Y u$ Y, Xu J, Shu H, Xia J, Liu H, Wu Y, Zhang L, Yu $Z$, Fang $M, Y u T$, Wang $Y$, Pan $S$, et al. Clinical course and outcomes of critically ill patients with SARS-CoV-2 pneumonia in Wuhan, China: a single-centered, retrospective, observational study. Lancet Respir Med. 2020; 8:475-81.

https://doi.org/10.1016/S2213-2600(20)30079-5 PMID:32105632

22. Mehra MR, Desai SS, Kuy S, Henry TD, Patel AN. Cardiovascular disease, drug therapy, and mortality in covid-19. N Engl J Med. 2020; 382:e102. https://doi.org/10.1056/NEJMoa2007621 PMID: $\underline{32356626}$

23. Rothstein A, Oldridge $O$, Schwennesen $H$, Do $D$, Cucchiara BL. Acute cerebrovascular events in hospitalized COVID-19 patients. Stroke. 2020; 51:e219-22. https://doi.org/10.1161/STROKEAHA.120.030995 PMID:32684145

24. Hernández-Fernández $F$, Sandoval Valencia $H$, Barbella-Aponte RA, Collado-Jiménez R, Ayo-Martín Ó, Barrena C, Molina-Nuevo JD, García-García J, Lozano-Setién E, Alcahut-Rodriguez C, MartínezMartín Á, Sánchez-López A, Segura T. Cerebrovascular disease in patients with COVID-19: neuroimaging, histological and clinical description. Brain. 2020; 143:3089-103. https://doi.org/10.1093/brain/awaa239 PMID:32645151

25. Zhang Z, Kim HJ, Lonjon G, Zhu Y, and written on behalf of AME Big-Data Clinical Trial Collaborative Group. Balance diagnostics after propensity score matching. Ann Transl Med. 2019; 7:16. https://doi.org/10.21037/atm.2018.12.10 PMID:30788363

26. Lian J, Jin C, Hao S, Zhang $X$, Yang $M$, Jin $X$, Lu Y, Hu J, Zhang S, Zheng L, Jia H, Cai H, Zhang $\mathrm{Y}$, et al. High neutrophil-to-lymphocyte ratio associated with progression to critical illness in older patients with COVID-19: a multicenter retrospective study. Aging (Albany NY). 2020; 12:13849-59. https://doi.org/10.18632/aging.103582 PMID:32730223

27. Barnes BJ, Adrover JM, Baxter-Stoltzfus A, Borczuk A, Cools-Lartigue J, Crawford JM, Daßler-Plenker J, Guerci P, Huynh C, Knight JS, Loda M, Looney MR, McAllister $F$, et al. Targeting potential drivers of COVID-19: neutrophil extracellular traps. J Exp Med. 2020; 217:e20200652.

https://doi.org/10.1084/jem.20200652 PMID:32302401

28. Osman J, Lambert J, Templé M, Devaux F, Favre R, Flaujac C, Bridoux D, Marque-Juillet S, Bruneel F, Mignon F, Diaz-Flores E, Hentgen V, Greder-Belan A, et al. Rapid screening of COVID-19 patients using white blood cell scattergrams, a study on 381 patients. Br J Haematol. 2020; 190:718-22.

https://doi.org/10.1111/bjh.16943 PMID:32542672

29. Chen XY, Huang MY, Xiao ZW, Yang S, Chen XQ. Lactate dehydrogenase elevations is associated with severity of COVID-19: a meta-analysis. Crit Care. 2020; 24:459.

https://doi.org/10.1186/s13054-020-03161-5 PMID:32709251

30. Han $Y$, Zhang H, Mu S, Wei W, Jin C, Tong C, Song Z, Zha $Y$, Xue $Y, G u$ G. Lactate dehydrogenase, an independent risk factor of severe COVID-19 patients: a retrospective and observational study. Aging (Albany NY). 2020; 12:11245-58.

https://doi.org/10.18632/aging.103372 PMID:32633729

31. de la Rica R, Borges M, Aranda M, Del Castillo A, Socias A, Payeras A, Rialp G, Socias L, Masmiquel L, GonzalezFreire M. Low albumin levels are associated with poorer outcomes in a case series of COVID-19 patients in Spain: a retrospective cohort study. Microorganisms. 2020; 8:1106.

https://doi.org/10.3390/microorganisms8081106

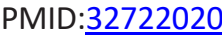


32. Bi X, Su Z, Yan H, Du J, Wang J, Chen L, Peng M, Chen S, Shen B, Li J. Prediction of severe illness due to COVID19 based on an analysis of initial fibrinogen to albumin ratio and platelet count. Platelets. 2020; 31:674-79. https://doi.org/10.1080/09537104.2020.1760230 PMID:32367765

33. García Virosta M, Ortega I, Ferrero E, Picardo AL. Diagnostic delay during the COVID-19 pandemic: liver abscess secondary to acute lithiasic cholecystitis. Cir Esp. 2020; 98:409.

https://doi.org/10.1016/i.ciresp.2020.04.010

PMID:32408994

34. Liu J, Tao L, Gao Z, Jiang R, Liu M. Development and validation of a prediction model for early identification of critically ill elderly COVID-19 patients. Aging (Albany NY). 2020; 12:18822-32.

https://doi.org/10.18632/aging.103716

PMID:33024057

35. Yu Y, Wang X, Li M, Gu L, Xie Z, Gu W, Xu F, Bao Y, Liu $\mathrm{R}, \mathrm{Hu} \mathrm{S}, \mathrm{Hu} \mathrm{M}, \mathrm{Hu} \mathrm{C}$. Nomogram to identify severe coronavirus disease 2019 (COVID-19) based on initial clinical and CT characteristics: a multi-center study. BMC Med Imaging. 2020; 20:111. https://doi.org/10.1186/s12880-020-00513-z PMID: $\underline{3008329}$
36. Fan $T$, Hao B, Yang $S$, Shen $B$, Huang $Z$, Lu Z, Xiong $R$, Shen $X$, Jiang $W$, Zhang $L$, Li $D$, He $R$, Meng $H$, et al. Nomogram for predicting COVID-19 disease progression based on single-center data: observational study and model development. JMIR Med Inform. 2020; 8:e19588.

https://doi.org/10.2196/19588

PMID:32866109

37. Pan D, Cheng D, Cao Y, Hu C, Zou F, Yu W, Xu T. A predicting nomogram for mortality in patients with COVID-19. Front Public Health. 2020; 8:461. https://doi.org/10.3389/fpubh.2020.00461 PMID:32850612

38. Interpretation of the diagnosis and treatment plan of corona virus disease 2019 (tentative sixth edition). Glob Health J. 2020; 4:9-10.

https://doi.org/10.1016/i.glohj.2020.03.003

PMID:32292831

39. Diagnosis and treatment plan of Corona Virus Disease 2019 (tentative sixth edition). Glob Health J. 2020; 4:1-5. https://doi.org/10.1016/j.glohj.2020.03.001 PMID: $\underline{32292830}$ 


\section{SUPPLEMENTARY MATERIALS}

\section{Supplementary Figure}

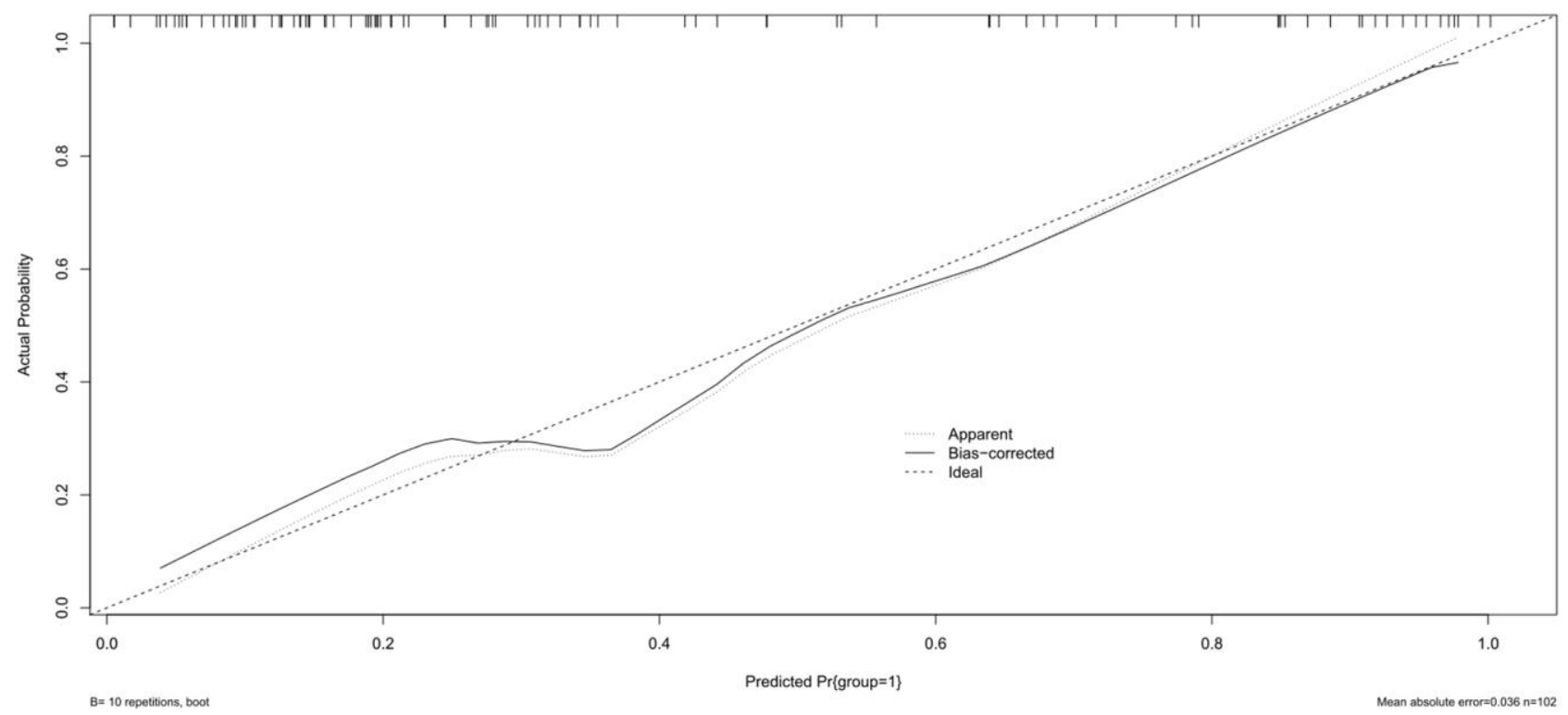

Supplementary Figure 1. Calibration curve of the nomogram prediction model for severe or critical COVID-19 relative to mild or ordinary COVID-19. 


\section{Supplementary Table}

Supplementary Table 1. The baseline characteristics of study patients with COVID-19.

\begin{tabular}{|c|c|c|c|}
\hline Characteristics & $\begin{array}{l}\text { Mild or ordinary cases } \\
\qquad(\mathrm{n}=326)\end{array}$ & $\begin{array}{l}\text { Severe or critical cases } \\
\qquad(n=44)\end{array}$ & $p$ \\
\hline Age (years) & $51(38,65)$ & $70(60,79)$ & $<0.001$ \\
\hline Males & $176(54 \%)$ & $24(54.5 \%)$ & 0.944 \\
\hline Contact with WH & $127(41.8 \%)$ & $40(90.9 \%)$ & $<0.001$ \\
\hline Death & $0(0 \%)$ & $16(36.4 \%)$ & $<0.001$ \\
\hline Hypertension & $63(19.4 \%)$ & $22(50 \%)$ & $<0.001$ \\
\hline Diabetes & $31(9.5 \%)$ & $11(25 \%)$ & 0.002 \\
\hline Smoking & $50(15.4 \%)$ & $6(13.6 \%)$ & 0.762 \\
\hline Cerebrovascular disease & $6(1.8 \%)$ & $5(11.4 \%)$ & $<0.001$ \\
\hline Cardiovascular disease & $10(3.1 \%)$ & $9(20.5 \%)$ & $<0.001$ \\
\hline Diagnostic delay (days) & $3(2,5)$ & $6(3,10)$ & $<0.001$ \\
\hline WBC & $4.400(3.400,5.595)$ & $5.600(4.450,7.800)$ & $<0.001$ \\
\hline NEUT & $61.70(53.80,69.50)$ & $81.10(67.80,89.70)$ & $<0.001$ \\
\hline LYMPH & $27.95(21.60,35.10)$ & $12.85(6.500,22.65)$ & $<0.001$ \\
\hline MONO & $7.100(5.200,9.200)$ & $4.250(2.600,7.200)$ & $<0.001$ \\
\hline NEUT $(\times 109 / \mathrm{L})$ & $2.640(1.900,3.660)$ & $4.635(2.940,6.690)$ & $<0.001$ \\
\hline LYMPH (×109/L) & $1.205(0.870,1.550)$ & $0.755(0.515,1.015)$ & $<0.001$ \\
\hline MONO $(\times 109 / \mathrm{L})$ & $0.300(0.230,0.400)$ & $0.280(0.200,0.365)$ & 0.159 \\
\hline PLT $(\times 109 / \mathrm{L})$ & $139(110,190)$ & $136(92,181.5)$ & 0.121 \\
\hline PCT (ng/mL) & $0.0800(0.0500,0.120)$ & $0.135(0.0800,0.265)$ & $<0.001$ \\
\hline TBIL $(\mu \mathrm{mol} / \mathrm{L})$ & $9.010(6.660,13.03)$ & $9.030(6.935,14.55)$ & 0.611 \\
\hline DBIL $(\mu \mathrm{mol} / \mathrm{L})$ & $2.310(1.550,3.420)$ & $3.100(2.250,4.970)$ & $<0.001$ \\
\hline $\operatorname{ALB}(\mathrm{g} / \mathrm{L})$ & $38.15(34.75,41.15)$ & $29.60(27.40,36.10)$ & $<0.001$ \\
\hline ALT (UL) & $21(14,33)$ & $23.50(14.50,34.50)$ & 0.695 \\
\hline AST (UL) & $21(16,28)$ & $24(21,36.50)$ & 0.006 \\
\hline $\mathrm{Cr}(\mu \mathrm{mol} / \mathrm{L})$ & $68.20(54.60,79.60)$ & $65.60(54.55,83.95)$ & 0.777 \\
\hline CK (UL) & $59(40,99)$ & $84(46,132)$ & 0.144 \\
\hline CKMB (UL) & $11.80(9.400,16)$ & $15.05(9.900,27.10)$ & 0.021 \\
\hline $\mathrm{CRP}(\mathrm{mg} / \mathrm{L})$ & $17.20(4,43.30)$ & $42.95(13.35,69)$ & $<0.001$ \\
\hline LDH (UL) & $202.5(163.5,258.5)$ & $315.5(217,454)$ & $<0.001$ \\
\hline HGB (g/L) & $122(111,134)$ & $114(98,122.5)$ & $<0.001$ \\
\hline
\end{tabular}

Abbreviations: WH, Wuhan; WBC, white blood cell; NEUT, neutrophil; LYMPH, lymphocyte; MONO, monocyte; PLT, platelet; $\mathrm{PCT}$, procalcitonin; TBIL, total bilirubin; DBIL, direct bilirubin; ALB, albumin; ALT, alanine transaminase; AST, aspartate aminotransferase; $\mathrm{Cr}$, creatinine; $\mathrm{CK}$, creatine kinase; $\mathrm{CKMB}$, creatine phosphokinase-isoenzyme-MB; $\mathrm{CRP}, \mathrm{C}$-reactive protein; $\mathrm{LDH}$, lactate dehydrogenase; HGB, hemoglobin. The $p$ value was calculated using the rank sum test or $\chi^{2}$ test where appropriate. Data are expressed as median (interquartile range) or count (percentage). 